\title{
Los Mora de Quintanar de la Orden: un criptojudaísmo familiar a finales del siglo XVI
}

Vincent PARELlo

Universidad de Montpellier III, Francia

\begin{abstract}
A finales del reinado de Felipe II, allá por los años 1588-1592, los inquisidores de Cuenca descubrieron en la villa de Quintanar de la Orden de La Mancha, una red de judaizantes autóctonos que seguían observando la religión de sus antepasados en una época en la que el Santo Oficio se había puesto al servicio de la Contrarreforma para castigar los delitos de los cristianos viejos e impedir la penetración de las ideas protestantes en el territorio español ${ }^{1}$.

Si bien se trata de una represión atípica, no fue la única por entonces en los reinos de Castilla. Así, el tribunal de Granada juzgó 221 causas de judaísmo entre 1529 y 1595 y los inquisidores del distrito de Murcia persiguieron a más de 550 personas acusadas de judaizar entre 1550 y $1570^{2}$. En los tribunales de Valencia, Barcelona y Zaragoza no se dieron tales represiones, por lo cual podemos afirmar que es un fenómeno puramente castellano.
\end{abstract}

\footnotetext{
${ }^{1}$ A la zaga de I. S. RÉVAH, el hispanista francés Charles AMIEL fue el primero en llamar la atención de los especialistas sobre el tema en los años 1980. De este autor, puede consultarse el siguiente artículo: «El criptojudaísmo castellano en la Mancha a finales del siglo XVI», en Judios, sefarditas, conversos: La expulsión de 1492 y sus consecuencias, Ángel AlCALÁ (ed.) (Valladolid 1995) págs. 503-512, y la introducción a su libro El siglo pitagórico o la vida de don Gabriel Guadaña (París 1977).

2 A. Domínguez OrTiz, Los judeoconversos en la España Moderna (Madrid: Mapfre, 1992) pág. 47; J. ConTrERAS, Sotos contra Riquelmes (Madrid: Mario Muchnik, 1992).
} 
A dicha red de complicidad de los Mora ya dedicamos un estudio ${ }^{3}$ en el que hacíamos hincapié en el impacto de la represión inquisitorial sobre el grupo familiar a la par que analizábamos las solidaridades familiares y económicas a cuya luz podía vislumbrarse la identidad de esa comunidad conversa. Sin embargo, apenas esbozamos allí el capítulo de las solidaridades entre marranos, por tratarse más bien de un tema de antropología religiosa que de historia de la familia. Esos aspectos son los que quisiéramos desarrollar ahora en el presente artículo.

En efecto, ¿a qué períodos de la historia del judaísmo peninsular aluden las causas de fe que hemos podido consultar en el Archivo Diocesano de Cuenca y en el Archivo Histórico Nacional de Madrid? ¿Cómo pudieron los Mora conservar su tradición religiosa y escapar del fenómeno de aculturación que se dio entre la mayoría de los conversos castellanos? ¿Cuáles eran los rasgos más representativos de la religión de los marranos practicada por esta comunidad manchega?

\section{El JUDAÍSMO CON SINAGOGA (FINALES DEL SIGLO XV - PRINCI- PIOS DEL XVI)}

En vísperas de la expulsión de los judíos de los reinos de Castilla decretada en 1492 por los Reyes Católicos, España ofrecía un panorama único en toda la cristiandad occidental; nos referimos a la presencia en un mismo territorio de tres comunidades étnicorreligiosas claramente diferenciadas: el pueblo cristiano de origen celtíbero, la comunidad mora de origen arábigo-beréber y la comunidad judía, cuya presencia milenaria se remontaba a la época de los romanos.

Con las conversiones masivas y forzadas iniciadas sobre todo a raíz de los violentos sucesos de 1391, cada una de esas comunidades adoptó el catolicismo, dando nacimiento a un nuevo tipo social, el cristiano nuevo, que designaba tanto al convertido de judío

\footnotetext{
${ }^{3}$ V. Parello, «La complicité des Mora de Quintanar de la Orden (15881592)», ponencia presentada en el coloquio sobre familias, poderes y solidaridades organizado en Montpellier (14-16 de diciembre de 2000) por la profesora MarieCatherine Barbazza (en prensa para las actas del coloquio).
} 
(judeoconverso) como al convertido de moro (morisco). Hasta la fecha de la expulsión convivieron en los reinos de Castilla comunidades de judíos oficiales que eran vasallos de la Corona y comunidades judeoconversas entre las que había una fuerte proporción de judaizantes. Estas fueron perseguidas por la Inquisición a partir de los años 1480; aquellas tuvieron que elegir entre el exilio o la conversión al cristianismo en 1492.

Ambas medidas formaban parte de una misma lógica: por un lado, se pretendía extirpar la herejía judaizante; por otro, arrancar de cuajo el estrecho vínculo que seguía uniendo a judíos y judeoconversos. Este argumento religioso aparece explícitamente en la «Real provisión de los reyes para la corona de Castilla firmada el 31 de marzo de 1492»:

... somos informados de los inquisidores y de otras muchas personas religiosas, eclesiásticas y seglares, consta y parece el gran daño que a los cristianos [nuevos] se ha seguido y sigue de la participación, conversación, comunicación que han tenido y tienen con los judíos, los cuales se prueba que procuran siempre, por cuantas vías y maneras pueden, de subvertir y sustraer de nuestra santa fe católica a los fieles cristianos y los apartar della ... ${ }^{4}$.

A través de las causas de fe de los Mora podemos remontarnos a la primera crónica del judaísmo castellano con la implantación de la Inquisición en Ciudad Real en 1483 y su traslado a Toledo en 1485 .

Hernando de Mora, mercader y tendero de especería oriundo de Alcázar de Consuegra, fue relajado al brazo seglar en la plaza de Zocodover de Toledo el 25 de septiembre de 1496 en presencia del corregidor, de los inquisidores y de los canónigos de la Catedral ${ }^{5}$. En 1588, por mandato de los señores inquisidores de Cuenca, el secretario Julián de Alpuche fue a buscar en la Cámara del Secreto de Toledo procesos, genealogías y sentencias referentes a los miembros de la familia Mora. Allí se encontró con la sentencia dada contra Hernando casi un siglo antes y por ella nos enteramos de que había sido reconciliado en tiempo de gracia después de

\footnotetext{
${ }^{4}$ Citado por J. PÉREz, Historia de una tragedia: La expulsión de los judios de España (Barcelona: Crítica, 1993) pág. 148. El decreto se halla en el Archivo General de Simancas, Patronato Real, leg. 28, fol. 6.

${ }^{5}$ Archivo Diocesano de Cuenca [= ADC], Inq., leg. 331 exp. 4733.
} 
haber abjurado de su crimen, pero que acto seguido «bolvyó a dezir e hazer el dicho crimen de heregía e apostasya».

El bachiller Diego Martínez de Ortega, promotor fiscal, le acusaba, entre otras cosas, de degollar las aves a modo judaico, de no comer tocino, de observar las pascuas judías, de mantener estrechas relaciones con la comunidad judía y de ver en la expulsión una señal de la Providencia para que los judíos pudieran pasar a Judea y practicar libremente su religión.

Como consta por las listas de judaizantes habilitados por la Inquisición de Toledo a finales del siglo XV, vivían en Alcázar de Consuegra unos 355 conversos (79 vecinos), que debían de representar más del $30 \%$ del conjunto de la población ${ }^{6}$.

En 1495, Hernando y su mujer Isabel Rodríguez pagaron la suma de 3.000 maravedís para poder llevar seda, oro, plata, perlas y piedras preciosas, tener armas, montar a caballo y gozar de las demás cosas arbitrarias prohibidas a los hijos y nietos de condenados por la Inquisición.

Por aquellos años Hernando no fue el único en caer en las garras del tribunal. Fueron perseguidos por motivos similares su suegra Marí López, hija de Pedro López Farín y de Catalina López, ambos relajados después de muertos por la Inquisición de Ciudad Real el 15 de marzo de $1485^{7}$, y su suegro, el procurador Juan González, cuyos huesos fueron quemados en Toledo durante el auto de fe de $1496^{8}$.

\section{EL JUDAÍSMO OFICIAL EN ORÁN (1509-1669)}

Después de 1492, fecha de la expulsión de los judíos y de la toma de Granada, ya no quedaban -en teoría- en los reinos de Castilla judíos oficiales. Todos eran cristianos, la mayoría cristianos viejos y los demás cristianos nuevos, recién convertidos al catoli-

\footnotetext{
${ }^{6}$ F. CAntera Burgos y P. León Tello, Judaizantes del arzobispado de Toledo habilitados por la Inquisición en 1495 y 1497 (Madrid 1969) pág. 98.

${ }^{7}$ H. BEINART, Records of the Trials of the Spanish Inquisition in Ciudad Real, 4 vols. (Jerusalén 1981) vol. IV pág. 477: «LOPEZ FARIN, PERO. Tried together with his wife Catalina. Their daughter, the wife of Diego, the money-changer, was summoned on 8 August 1484 to defend their memory (Trial No. 81, fols. 2r-3r). The couple were condemned; their bones were exhumed and burnt on 15 March 1485 ».

${ }^{8}$ Archivo Histórico Nacional [= AHN], leg. 154 exp. 365.
} 
cismo. Entonces fue cuando el problema judío dio paso al problema converso.

Contrariamente a lo que ocurrió en Portugal donde las comunidades marranas mantuvieron intacta su cultura y su tradición religiosa, en España a partir de los años 1520 se dio un fenómeno de aculturación general cuya consecuencia más inmediata fue la integración social y espiritual de los conversos en la sociedad mayoritaria a la par que la pérdida de sus señas de identidad cultural. Ese fenómeno se debió en gran parte a la actuación de la Inquisición que se ensañó contra el criptojudaísmo peninsular entre los años 1480-1520, destruyendo las sinagogas clandestinas y relajando y reconciliando a miles de familias de estirpe judaica.

Sin embargo, la historia siempre ofrece algunas rarezas y cada sociedad encierra sus propias contradicciones. Desde el principio de su reinado el emperador Carlos $\mathrm{V}$ tuvo que hacerse cargo del final del sueño de unidad religiosa y política del imperio, amenazado desde dentro por los adeptos de Lutero y desde fuera por los Turcos, lo que provocó un endurecimiento ideológico de su política castellana a partir de los años 1530-1540.

A la zaga de sus abuelos, los Reyes Católicos, se lanzó a una especie de cruzada interna contra los luteranos, los moriscos y los conversos para lograr implantar la unidad del catolicismo en sus reinos. Pese a ello, el monarca dio preeminencia en algunos casos al principio de «racionalidad económica» a costa del principio de «racionalidad religiosa» 9 .

En Orán, presidio conquistado en 1509 por el cardenal Cisneros, entonces arzobispo de Toledo, se habían refugiado miembros de la diaspora sefardí procedentes de la expulsión de $1492{ }^{10}$.

A finales del siglo XVI la comunidad judía del presidio debía de rondar los 450 individuos, a los que se permitía morar en la ciudad cristiana junto con los musulmanes y que gozaban del estatuto de vasallos de la corona.

Así, los Reyes Católicos, Carlos V y luego Felipe II entregaron sucesivamente la ejecución de parte de su política mediterránea a

\footnotetext{
${ }^{9}$ Sacamos estos conceptos de la obra de Raymond ARON, Plaidoyer pour l'Europe décadente (París 1977) pág. 85.

${ }^{10}$ Sobre este asunto apasionante, véase el libro de Jean-Frédéric SCHAUB, Les juifs du roi d'Espagne: Oran 1509-1669 (París: Hachette, 1999).
} 
unos súbditos judíos que se impusieron como preciosos intermediarios diplomáticos y comerciales con las poblaciones musulmanas e intérpretes imprescindibles por su buen conocimiento del castellano, del arábe y del hebreo. Esta política ambigua de frontera y de mestizaje terminó en 1669 cuando la reina regenta, en nombre del rey Carlos II, decretó la expulsión de todos los judíos oraneses.

De dicha supervivencia de la «España de las tres religiones» en la España de la Contrarreforma fueron testigos María de Mora, esposa de Pedro de Sauca, y Cristóbal de Mora Molina, hijo del difunto Juan de Mora.

En la audiencia del 19 de junio de 1589, María refirió ante el inquisidor don Francisco de Arganda una conversación que su padre Diego de Mora tuvo con un escribano que se decía Molina y otro juez de escribano que moraron en su casa allá por los años 1572:

abrá tiempo de diez y siete años que, posando un escrivano que se dezía Molina en casa de Diego de Mora, padre desta declarante, que venía con un juez de escrivano, que no se acuerda esta declarante quien hera, hablando con el dicho Diego de Mora su padre, que lo oya esta declarante, le dixo que havía estado en Orán y en otras partes, y entre otras cosas, le contó que en Orán havía judíos que libremente bivían en su ley y que se salían al campo y dezían que iban a esperar el mexías, y que dezían estas palabras «cumple señor lo que prometiste» ${ }^{11}$.

Cuando tenía aproximadamente veinte años, Cristóbal Mora Molina se fue a Murcia donde se embarcó como soldado de infantería en la armada del capitán Pellicer. Anduvo por la mar siete u ocho meses e hizo una primera escala en Orán donde pudo entrar en contacto con unos judíos que practicaban oficialmente la ley mosaica ${ }^{12}$. Podemos imaginar el asombro que debió de producir en la mente del joven soldado semejante hallazgo.

\section{El JUDAÍSMO SIN SINAGOGA A FINALES DEL SIGLO XVI}

Salvo contadas excepciones, la Inquisición dejó de perseguir a los descendientes de Hernando de Mora hasta los años finales del siglo XVI.

11 ADC, leg. 324 exp. 4651.

12 ADC, leg. 321 exp. 4621. 
En efecto, la política inquisitorial cambió de rumbo bajo Carlos V y Felipe II. Abandonó parcialmente el delito de criptojudaísmo y se puso al servicio de la Contrarreforma, luchando contra el luteranismo y contra los moriscos que seguían practicando a escondidas el islam, castigando los delitos para-heréticos de los cristianos viejos -tales como la blasfemia, la bigamia, las proposiciones, etc.-, persiguiendo las sectas heterodoxas -como el erasmismo, el iluminismo y la mística-, y controlando el pensamiento a través de los Índices, que fueron multiplicándose a partir de 1551.

Entre 1588 y 1592, cuando parecían haber desaparecido para siempre las sinagogas clandestinas del horizonte castellano, los inquisidores de Cuenca desmantelaron, con la ayuda de testigos externos y de las mismas víctimas, una «complicidad» de judaizantes autóctonos en Quintanar de la Orden. Entre las sesenta y tres personas condenadas, diecisiete fueron relajadas al brazo seglar (cinco en presencia y doce post mortem), treinta y cinco reconciliadas, tres suspensas y otras tres condenadas a penas pecuniarias. De cinco procesos desconocemos el fallo dado por el tribunal.

Casi todos los miembros de la familia Mora salieron en los dos autos de fe que tuvieron lugar en la Plaza Mayor de Cuenca el 12 de agosto de 1590 y el 16 de agosto de 1592. A modo de ejemplo, Beatriz, hija del difunto Hernando de Mora, fue relajada al brazo seglar durante el primer auto de fe conquense. He aquí un fragmento del final de su sentencia:

... declaramos la dicha Beatriz de Mora haver sido y ser herege, apóstata, fautora y encubridora de hereges, y por ello haver caydo e incurrido en sentencia de excomunicación mayor, y en confiscación y perdimiento de todos sus bienes, los quales mandamos aplicar y aplicamos a la cámara y fisco de Su Magestad y a su receptor en su nombre, desde el día y tiempo que començó a cometer los dichos delictos de heregía cuya declaración en nos reservamos, y debemos relaxar y relaxamos la persona de la dicha Beatriz de Mora a la justicia y braço seglar, especialmente a don Lorencio Suárez de Mendoça, corregidor desta ciudad y a su lugar tiniente en el dicho officio, a los quales rogamos y encargamos muy affetuosamente como de derecho mejor podemos, se hayan benigna y piadosamente con ella y por esta nuestra sentencia deffinitiva juzggando ansí lo pronunciamos y mandamos en estos escriptos ${ }^{13}$.

${ }^{13}$ ADC, leg. 318 exp. 4586. 
La supervivencia de un criptojudaísmo residual entre los Mora puede explicarse en parte por unos factores de coyuntura externa e interna. Por un lado, es obvio que los Mora gozaron de una tregua inquisitorial entre 1520 y 1580.

A mitad del siglo XVI los inquisidores de Toledo tenían la íntima convicción de haber extirpado la herejía judaizante de la zona meridional de su distrito como consta por una carta del licenciado Yáñez enviada a la Suprema el 29 de agosto de 1553 en la cual explica que «no parecen çerimonias de judíos» en Ciudad Real, en el Campo de Calatrava y en el Priorazgo de San Juan ${ }^{14}$.

Paralelamente, los inquisidores de Cuenca desatendieron la parte manchega de su distrito, que no volvieron a visitar a partir de los años 1520. En efecto, pensaban que la primera represión llevada a cabo en el Priorato de Uclés y en el marquesado de Villena había bastado para eliminar para siempre las comunidades de marranos autóctonos de la zona. Por eso, prefirieron visitar la parte norte del obispado, mayormente las villas de Medinaceli, Deza y Arcos de Jalón, en los estados del duque de Medinaceli, por la presencia masiva en ellas de comunidades moriscas que planteaban un peligro político y social. En una carta fechada el 18 de enero de 1570 el inquisidor Reinoso explicaba al Consejo de la Suprema que «sería de más ymportancia estar aquí [en Arcos de Jalón y en Deza] que salir a visitar La Mancha donde se cree por la bondad de Dios que ya no ay hereges» ${ }^{15}$.

Por otro lado, los Mora supieron mantener unas solidaridades económicas, familiares y religiosas muy eficaces y originales. Era en la intimidad de la familia donde residía la clave de todos los éxitos. Se casaban entre ellos, pasando a veces por alto las prescripciones canónicas que vedaban los casamientos consanguíneos hasta el cuarto grado de parentesco. Solían emparentar con un número muy limitado de familias conversas oriundas de las provincias de Cuenca y de Toledo, como los López de Armenia, los Vega-Ruiz, los Villanueva, los Gómez-Bedoya, los Moya, los Navarro, los Campo, los Carrillo, los Falcón, los Enríquez y los Villaescusa. Además trabajaban juntos y al margen de sus activida-

${ }_{14}$ AHN, Inq., leg. $3067 \exp 63$.

15 Citado por Rafael CARrasco, «Preludio al siglo de los portugueses: La Inquisición de Cuenca y los judaizantes lusitanos en el siglo XVI», Hispania 47 (1987) págs. 503-559: pág. 523. 
des agrícolas y ganaderas, formaban pequeñas compañías de comercio y de arrendadores de rentas.

En cuanto al criptojudaísmo se transmitía oralmente de generación en generación en el marco de la familia y en el espacio de la casa mediante los «dogmatizadores» o «enseñadores» de la ley mosaica que desempeñaban el papel de depositarios de la memoria colectiva. También podían tomar el relevo los libros, mayormente la Biblia en lengua vulgar, los manuales de devoción y de piedad y la literatura mística, así como los Edictos de fe -inventarios de las prácticas y de las afirmaciones heréticas criptojudías que se proclamaban durante las visitas inquisitoriales-, los autos de fe y los sermones antes de Cuaresma ${ }^{16}$.

\section{El marranismo de los Mora de Quintanar de la Orden}

En primer lugar, llama la atención la conciencia que tenían los Mora de pertenecer a la «casta» y a la «generación» de los cristianos nuevos de judíos descendientes de la casa de Israel. Se definían, pues, como un grupo étnico-social aparte que vivía al margen de la sociedad mayoritaria cristiana vieja.

Esta conciencia de la alteridad resulta fundamental para comprender la identidad del grupo. Juan de Mora, por ejemplo, transformaba en título de nobleza lo que se consideraba en aquel entonces como una terrible mácula: «preciándose de la casta y generación que era, no tenía por affrenta que le llamasen judío, antes se holgava dello» ${ }^{17}$.

De la misma manera, Cristóbal de Mora Molina, hijo del difunto Juan de Mora, sabía perfectamente que era converso y nieto de condenado por la Inquisición, tal como lo declaró ante los inquisidores el 2 de octubre de 1590:

es de generación de conversos y lo son los que tiene dicho según a oydo dezir, y que éste no a seydo presso ni penitenciado por el santo officio, y que una aguela deste de parte de su padre fue penitenciada por este santo officio a lo que a oydo dezir, y que no sabe cómo se llamava ... ${ }^{18}$.

${ }^{16}$ Ch. AmIEL, «Crypto-judaïsme et Inquisition. La matière juive dans les édits de la foi des Inquisitions ibériques», Revue de l'Histoire des Religions 210/2 (1993) págs. $145-168$.

17 ADC, leg. 318 exp. 4587.

18 ADC, leg. 321 exp. 4621. 
Como todos los marranos, los Mora eran cristianos de fachada y judíos en su fuero interno. Consecuencia de un doble rechazo del catolicismo y de una aculturación con respecto al judaísmo, el marranismo constituía una heterodoxia tanto desde el punto de vista judío como cristiano.

Al tratarse de una religión no oficial, sus adeptos tenían que practicarla en la mayor clandestinidad. A modo de ejemplo, Beatriz de Mora, que hablaba por propia experiencia, no se fiaba de los criados porque podían denunciar ante el Santo Oficio las prácticas religiosas heréticas de sus amos:

aunque ella y otras personas se podían servir de criados, no lo hazían diziendo que descubrían lo que passaba en casa, y que así lo havían hecho de cierta persona su conjunta que havía sido castigada por el santo officio ${ }^{19}$.

En esta atmósfera de sospecha generalizada, los Mora debían vigilarse constantemente y reproducir la mirada del observador externo. Obligados a esconderse, a disimular, acabaron adoptando una postura irónica frente a la sociedad y el mundo. Dicha actitud era perceptible, en particular, a través del lenguaje.

Muchos hablaban en clave y cultivaban el doble lenguaje. De esta manera, el adjetivo limpio podía aplicarse a una comida «que no lleva tocino»; el participio relajado significa «muerto mártir» desde una perspectiva judía; la expresión rezar en la parroquia de Santa María de la Piedad, antigua sinagoga medieval, «adorar al Dios de Israel»; etc.

En la acusación criminal redactada el 24 de octubre de 1597 contra Francisca de Mora, mujer de Hernando de Sauca, el promotor fiscal, el licenciado Joan de Ochoa, alude a este «lenguaje secreto» de los conversos de Quintanar de la Orden:

No comía [Francisca de Mora] tocino ni lo hechaba en la olla de que havía de comer, y convidando a cierta persona de su casta y generación una vez a comer de su olla, le dixo que bien podía comer della que limpia estaba, dando a entender por las dichas palabras que no tenía tocino, lenguaje secreto y ordinario entre los que de la dicha villa del Quintanar han guardado y vivido en la ley de Moysen ${ }^{20}$.

${ }^{19}$ ADC, leg. 318 exp. 4586.

${ }^{20}$ ADC, leg. 314 exp. 4555. 
En la sentencia dada a continuación los inquisidores recalcan este fenómeno de duplicidad linguística:

aviendo conbidado a comer a una de las dichas personas, le avía hecho lavar las manos primero que comiese, diziéndola que bien podía comer de su olla y que estaba limpia, dándole a entender que no tenía tocino, el qual lenguaje y modo de dezir avía sido muy usado y guardado entre ella y las demás personas de su profesión para significar en cifra quando no tenía tocino la olla y el dezir que estaba sucia quando le tenía ${ }^{21}$.

Si los Mora conocían los rudimentos de la fe católica (cuatro oraciones, diez mandamientos, señal de la cruz, etc.) como cualquier otro cristiano viejo de la época, el catolicismo seguía siendo para ellos una mera farsa social, una mera religiosidad externa.

Para los inquisidores eran ante todo unos heteredoxos, es decir, unos malos cristianos que se habían alejado de los preceptos dados por la Santa Madre Iglesia de Roma y establecidos por el Concilio de Trento. Entre las acusaciones más frecuentes encontramos el quebrantar los domingos y fiestas cristianas, el no tener en casa cruz ni imágenes de santos y el comer carne durante la Cuaresma.

Algunos miembros de la familia Mora llegaron a ridiculizar y a escarnecer la religión de Cristo. Por la Semana Santa de 1585 Beatriz de Mora fue hallada

con ciertas personas de su casta y generación muy encerrada en su casa, adereçada su persona y rostro, muy alegre en tiempo que la santa iglesia hazía sentimiento universal por la muerte y pasión de Jesu Cristo Nuestro Señor ${ }^{22}$.

Para injuriar y ofender a Cristo, Francisco de Mora el Viejo poseía un crucifijo en un palomar y allí

con gran maldad y perfidia le açotava, pisava y escarneçía, y es de creer que le tenía allí para açotalle, pisalle y escarneçelle todas las vezes que fue al campo ${ }^{23}$.

\footnotetext{
21 Idem.

${ }^{22}$ ADC, leg. 318 exp. 4586.

${ }^{23}$ ADC, leg. 711 exp. 753.
} 
Ana de Mora, hija de Francisco de Mora,

nunca tomaba en su voca el santísimo nombre de Nuestro Señor Jesucristo para alavarle ni para invocarle en sus necesidades, y es de presumir que no cree en él ${ }^{24}$.

Fuera de estas manifestaciones externas de heterodoxia, los inquisidores se mostraban muy preocupados por la presencia de ciertos libros en casa de los Mora. Se trataba, mayormente, de novelas de caballerías, de la Biblia en romance, de manuales de devoción y de piedad como el Flos sanctorum de Alonso de Villegas publicado en 1588, las Horas de Nuestra Señora, un libro de Salmos de San Benito, la Torre de David o el Espejo de consolación, y de literatura mística con obras de fray Luis de Granada.

En el Índice del inquisidor general Valdés publicado el 17 de agosto de 1559 , y más precisamente en su sección castellana, figuraban numerosos libros de piedad y de devoción y libros de espiritualidad publicados después de 1540, tales como el Libro de la oración y meditación (1554) y la Guía de pecadores (1556) de fray Luis de Granada. No sólo quería luchar la Inquisición contra la propaganda luterana sino que también deseaba cortar de raíz todas las facetas de la vida espiritual castellana. Los inquisidores sabían que a los cristianos nuevos podían seducirles esas nuevas formas de cristianismo interiorizado alejado de las ceremonias y formalismos externos y por eso intentaban controlarlas.

Interrogados por los inquisidores, los Mora confesaban haberse educado en la Antigua Ley, o sea, la ley pactada entre Dios y Moisés, en oposición a la Nueva Ley, atribuida a los Evangelios, a los Apóstoles, a las Epístolas y al Apocalipsis. Mientras que el catolicismo creía en una Nueva Alianza entre Dios y la humanidad a través de Cristo y, por lo tanto, según los términos empleados por los inquisidores, consideraba la Antigua Ley como "pérfida, caduca y mortífera», el judaísmo seguía afirmando que la Alianza entre Dios y el pueblo de Israel siempre sería válida y nunca podría caducar.

Así, Beatriz, hija de Hernando de Mora, declaró ante los inquisidores conquenses que

${ }^{24}$ ADC, leg. 320 exp. 4619. 
su trato, pláticas e vivienda era muy diferente de la de los cristianos viejos por que todas sus conversaciones eran del Testamento Viejo y de las profecías de la venida del Mexías y de quando Dios le había dado la ley a Moysén ${ }^{25}$.

En 1590, Luisa, hija del difunto Juan de Mora, explicaba ante el tribunal que se arrepentía sinceramente de haber vivido en la ley de Moisés y que ahora entendía «que aquello avía cesado con averse hecho hombre Jesu Cristo y derramado su sangre por la redención de los hombres» ${ }^{26}$.

Salvo contadas excepciones los Mora seguían aferrados a su antigua ley y negaban rotundamente la venida del Mesías en la persona de Jesucristo. Hernando de Mora y su hijo Álvaro siempre tuvieron la ley de Moisés por buena, pensaban salvarse en ella y hasta su muerte

avían negado la venida del Messías y no creydo en Jesu cristo nuestro señor, ny que con su muerte y passión ubiese obrado la redempción del género humano ${ }^{27}$.

Si en lo social los Mora practicaban formas de religiosidad cristiana, en la intimidad del hogar seguían los preceptos de la ley mosaica, que pueden agruparse principalmente en tres categorías: las fiestas religiosas, las costumbres alimenticias y las prácticas higiénicas, y los ritos propios del nacimiento y de la muerte.

Como es de suponer los Mora observaban el sábado en recuerdo del séptimo día en que Dios descansó de su obra creadora. A partir del viernes por la tarde barrían y fregaban la casa, cambiando las sábanas y poniendo manteles limpios se aseaban y vestían camisas nuevas, aderezaban los candiles que luego dejaban encendidos durante toda la noche y guisaban la adafina, especie de estofado cocido a fuego lento que habían de comer al día siguiente. El sábado no hacían ninguna obra servil, se visitaban unos a otros y se juntaban bajo la tutela de un «dogmatizador» para leer fragmentos de la Biblia y rezar algunos salmos.

Asimismo observaban las tres pascuas judías: Sukot, o la Pascua de las Cabañuelas, en septiembre u octubre, en memoria de los

\footnotetext{
${ }^{25}$ ADC, leg. 318 exp. 4586.

26 ADC, leg. 331 exp. 4734.

27 ADC, leg. 320 exp. 4618.
} 
beneficios que Dios hizo al pueblo de Israel en su peregrinación por el desierto durante cuarenta años «sin que se les gastasen las vestiduras, dándoles de comer codornizes y maná, con favor y gusto de todo lo que querían»; Pésah, o la Pascua del Cordero, poco antes de la Pascua de Resurrección, para celebrar la liberación de los hijos de Israel de la servidumbre de Egipto y su nacimiento como pueblo libre; y Šabu'ot, o Pascua de Pentecostés, cincuenta días después de Pésah, para dar gracias al señor «por haver dexado coger los frutos de la tierra».

Catalina de Villanueva, la mujer de Francisco de Mora, alude en su proceso a la Pascua del Cordero, según el relato bíblico de cómo se señalaron las puertas de los judíos con la sangre del animal para librarse de la última plaga, la muerte de los primogénitos:

enbió Dios al Ángel para que con la sangre del cordero señalase las casas, y que venía hiriendo por el camyno, y que las casas que abía de señalar heran las de los judíos y que en ellas no abía de herir por estar señaladas, y que judío quiere dezir hombre justo ${ }^{28}$.

Durante las pascuas los Mora solían dar limosna a los cristianos nuevos desamparados y convidarse unos a otros.

Además del sábado y de las tres pascuas, respetaban los ayunos mayores y menores: Yom Kipur, Purim, y los ayunos del lunes y del jueves, que tenían un carácter facultativo.

Escuchemos la acusación del promotor fiscal contra Antonio Martínez de Mora, hijo del difunto Juan de Mora:

Ha ayunado en compañía de otras personas sus conjuntas el ayuno mayor de los judíos por espacio y tiempo de diez días continuos començando el primer día de la luna del mes de septiembre exclusive y los sávados que tampoco no los ayunaba no comiendo ni veviendo en todo el día asta salida la estrella, y entre año otros muchos días como son los domingos, lunes y juebes, y otros ayunos que llamen ellos dobles y tras dobles rezando en los tales días cierto número de vezes ciertas orationes judiegas ${ }^{29}$.

${ }^{28}$ ADC, leg. 711 exp. 753.

${ }^{29}$ ADC, leg. 324 exp. 4652. 
Por lo que se refiere a las costumbres alimenticias, los Mora no comían carne de cerdo ni tocino, amasaban el pan cenceño sin levadura, comían carne muerta con rito y ceremonia de la ley de Moisés, guisaban la adafina los viernes por la noche, etc.

Era sin duda la matanza ritual la que más llamaba la atención de los testigos y de los inquisidores. Ninguno de los Mora compraba carne de la carnicería, ni comía carne ahogada o mortecina. La matanza constaba de tres etapas: primero, se degollaba al animal puesto hacia el sol poniente atravesándole el cuchillo por la nuca; luego, se le desangraba poniéndolo a remojar con sal y agua; y por último, se le quitaba el sebo y la «landrecilla», es decir, el nervio ciático. Durante la matanza de la res o del ave, los participantes solían rezar una bendición como «vendito sea aquel que te crió para la muerte y para el mantenimiento de la gente».

Las matanzas daban lugar a verdaderas reuniones familiares. A veces los Mora incluso convidaban a su mesa a comensales moriscos que venían a compartir con ellos la «carne muerta con ceremonia de la ley de Moysen».

Antonio, hijo de Juan de Mora, había matado alguna oveja en el patio de la casa de su hermano Francisco Martínez de Mora «atravesando el cuchillo por la nuez», y luego la había comido con su tío Diego de Mora y su mujer María de Villanueva, sus primos $\mathrm{y}$ algunos moriscos ${ }^{30}$.

Al margen de las reglas alimenticias, los Mora respetaban de manera muy estricta las de la pureza ritual, que consistían en cortarse las uñas de las manos y de los pies, y lavarse todo el cuerpo (tebilá) o las manos únicamente (netilat yadayim) antes de comer o de rezar, durantes las fiestas, en período de menstruación, tras el contacto con un muerto, etc.

Poco antes de morir Diego de Mora puso la mano sobre la cabeza de su hijo Francisco para bendecirle tal como lo hizo Jacob con sus nietos Manasés y Efraín, a la par que le explicó que «estando su muger [Leonor Enríquez] con su regla no llegase a ella porque hera peccado mortal por respeto de la sangre» ${ }^{31}$.

Francisca, Luisa e Isabel de Mora volvían boca abajo las escudillas en que comían «porque no las lamiesen los perros, ni los ga-

${ }^{30}$ ADC, leg. 324 exp. 4652.

31 ADC, leg. 319 exp. 4607. 
tos, porque por ser animales inmundos era prohibido en la dicha ley» ${ }^{32}$.

En los procesos encontramos indicaciones sumamente interesantes sobre las oraciones recitadas por los miembros de la familia Mora. Se trata principalmente de la «Šemá», o profesión de fe del judaísmo (Deut 6:4), del «Alenu» y del «Canto grados», himnos y alabanzas que celebraban el papel de creador y de redentor del Dios de Israel.

Con relación al «Alenu», una de las oraciones judías más antiguas, recordemos que se presenta bajo la forma de una profesión de fe dividida en dos partes: la primera, sobre el papel de Israel como pueblo elegido; y la segunda, que afirma la omnipotencia divina y expresa la esperanza universal de un «mundo mejor bajo el reino del Todopoderoso».

En cuanto al «Canto grados» se trata de una oración muy difundida entre los conversos castellanos desde finales del siglo XV para solicitar la protección y el amparo del Señor, que así comienza: «Canto grados, cuando alçaré al señor mis ojos, a los montes, a los montes del señor, etc.».

A esas tres oraciones hay que añadir salmos y canciones «sacadas de fuentes judías, escriturarias, rabínicas o folklóricas» ${ }^{33}$, como «De que el Señor probó a Abraham», "Cuando la Casa estaba enhiesta», "Alabado aquel que taja y afirma», "Alabado seas tu Señor que mandaste fender la peña», «Líbrame señor como libraste a Daniel», etc.

A modo de conclusión, diremos que el grupo de los Mora de Quintanar de la Orden, perseguidos a finales del siglo XVI por la Inquisición de Cuenca y de Toledo, plantea problemas interesantísimos tanto desde el punto de vista religioso como cultural. Leyendo los procesos se puede llegar a reconstruir la crónica del criptojudaísmo peninsular que abarca dos etapas principales: el criptojudaísmo con sinagoga de finales del siglo XV y principios del siglo XVI, y el criptojudaísmo sin sinagoga de finales del siglo XVI.

A esos dos períodos cabe añadir el judaísmo oficial presente en Orán entre 1509 y 1669, ejemplo de supervivencia de la «España de las tres religiones» en la España de la Contrarreforma.

${ }^{32}$ ADC, leg. 314 exp. 4555.

33 AMIEL «El criptojudaísmo castellano» pág. 508. 
El criptojudaísmo de los Mora se presenta como un marranismo residual, autóctono, que no tiene nada que ver con la historia de los marranos portugueses, quienes por motivos demográficos, económicos e ideológicos vinieron a refugiarse masivamente en Castilla a partir de 1580, fecha de la unión dinástica de España y Portugal bajo el reinado de Felipe II.

Por motivos coyunturales externos (tregua inquisitorial entre 1520 y 1580 en la zona meridional del distrito conquense) e internos (muy fuerte solidaridad familiar, económica y religiosa en el seno del grupo), los Mora pudieron mantener intacta su cultura y escapar así de la aculturación general que había alcanzado a la gran mayoría del colectivo converso.

Heteredoxos y herejes a la vez, siguieron practicando los preceptos de la ley mosaica y rezando las oraciones de sus antepasados como la «Šemá», el «Alenu» y el «Canto grados».

Esperamos que la próxima publicación del libro del profesor Charles Amiel venga a aportarnos nuevos y definitivos datos sobre esta comunidad de judaizantes manchegos y renovar nuestros actuales conocimientos sobre la historia del criptojudaísmo peninsular.

\section{APÉNDICE 1}

PRINCIPALES ORACIONES JUdíAS RECOGIDAS EN LOS PROCESOS DE LOS MORA DE QUinTANAR DE LA ORDEN

1. Oración de la mañana (ADC, leg. 324 exp. 4651)

Alabado seays vos Señor que me levantastes biva y sana y me levantastes con el ánima en las carnes y me distes lienço y paños que vistiese, distesme Señor coraçón con que pensase y boca con que hablase, ojos que viese y oydos con que oyese, no alabava yo vuestro santo nombre, dormía como una muerta, plegue a tu nombre santo que todas las oras que me dieres de bida las gaste yo en tu servicio. Amén.

2. Oración para lavarse las manos antes de comer (ADC, leg. 314 exp. 5555)

Alabado seas tu Señor que mandaste fender la peña, a Moysén para sacar las aguas claras y hazernos limpios de manos ... 
3. Oración para después de lavarse las manos (ADC, leg. 321 exp. 4621)

Bienaventurada es la persona que de vos se confía, Señor, y en vos espera con limpieça de manos, voz templada cotidianamente, a ti alava Dios mío tres vezes al día, recuenta tus loores según la costumbre de David tu siervo, mas si es aventurada la persona que se enfinca en la vanidad del mundo, que en abriendo los ojos del sueño tiende sus manos a obras mundanas, menospreciará los loores y alabamientos del Señor, diziendo que su trabajo le mantiene por sus trabajos y loores, no bastarán riqueças, bienes ni valentías ante los principales del pueblo, porque ciertamente es el Señor el que mantiene y sostiene toda cosa viva, todo sobre todo quien da honrra sin vituperios y olgança sin turbaciones, sino el rey de la gloria que puso en las alturas sus altas moradas, a los vivos visita con su mano, y acata las vejezes de la tierra, la casa de Ysrrael amástela, ley y mandamientos, fueros y juizios ...

\section{Cuando el Señor probó a Abraham (ADC, leg. 314 exp. 4621)}

«Abrahán toma tu fijo amado y llévalo al monte de Sinai y sacrifícamelo a mí». Abrahán se levantó por la mañana y tomó a su fijo por la mano y dixo «veo el cuchillo y no veo el carnero de que se a de fazer el sacrificio. Fijo mío el criador lo depara que de ti lo tengo que hazer». «Pues, padre, tapadme los ojos porque no los alçe ayrados contra vos». Entonces vino a hazer sacrificio de su hijo, viene la boz del ángel del çielo: «Abrahán, no tiendas la mano al moço que visto al Señor la tu voluntad». Entonces rodeó Abrahán la cabeça y vido un carnero travado por los cuernos en una çarza y hizo sacrificio y recibimiento al Señor, entonces bendixo al Señor. «Abrahán, tu generaçión será multiplicada como las estrellas que son en el çielo y las arenas, que son sobre las orillas de la mar, que no escusaste tu hijo amado de mí».

\section{La «Šemá » ${ }^{34}$ (ADC, leg. 316 exp. 4572)}

Amarás Adonay tu Dios con todo tu coraçón tomando aquestas palabras que te mando el día de oy sobre tu coraçón, sobre tu alma y sobre tu hazienda rezándolas a tus hijos. Serán, si lo oyeres, los mandamientos que oy encomiendo a vosotros el día de oy, cogeréis vuestros açeites y vuestras çiberas, dará el Señor la yerba

\footnotetext{
${ }^{34}$ El texto contiene realmente la «Šemá"», las bendiciones que le siguen y el
} principio de la «"Amidá». 
en vuestros campos para vuestras bestias, para vuestros ganados, comeredes, hartarosedes y seréis hartos. Guardaos no trastornen vuestros coraçones a servir dioses agenos, no os humilledes a ellos, sino vendrá la saña del Señor contra vosotros, no será la lubia en la tierra, perderosedes ayna sobre la tierra buena que juró de darla el Señor a sus anteçesores, darlaedes tanto quanto diziendo habla, vee a los hijos de Ysrael que hagan çezi y pondrán las alas en el çezi hilo de carde que sea a vosotros por ciçi por los quales seréis santificados a vuestro Dios, que yo soy vuestro Dios y vuestro criador que saqué a vosotros de la tierra de Egipto y seré a vosotros por Señor, bendito nuestro Dios o verdadero fiel amado, abastado, codiçiado, regidente, amigable, firme, gracioso, derechero, complido, esmerado, esmera aquestas palabras sobre nos, que vos soys Adonay, nuestro Dios, el que nos redime de mano de los reyes, el que nos redime de mano de los esforçados, el que puso nuestros ánimos en la vida, el que nos libró de Faraón con señales y con pruevas, firió con su saña, sacó a su pueblo de Ysrael a soltura de la partiçión de la mar bermeja, allí vieron sus hijos sus barraganías, sus grandeças, todos a una boca dixeron, el Señor en reyno gran día se vistió, vistió el Señor fortaleza, se ciñó también adereço, el mundo que no se acueste ni se desfaga que adereçada su silla de antes y siempre y después, que no ay tortura en ella, eres tu Adonay y mi Dios y mi Señor Adonay en reyno, gran día se vistió la graçia del Señor, deziendan sobre mí, sobre aquellos que dizen tres veces en el día bendito sea el Señor de día, bendito sea el Señor de noche, el Señor sea en mi hechada, el Señor sea en mi levantada, Señor abrí mi boca para que denunçie tu loor, vendito vos, Señor, Dios de mis parientes, Dios de Abraham, Dios de Ysac, Dios de Jacob, el alto, el poderoso que sostiene a los caydos, mediçináis los enfermos, soltáis los pressos, firme soys en la vuestra verdad, los que hazen el polbo de la tierra a vos, Señor de las barraganías, quien ay que semege a ti, rey matador, avediguador, hazedor de la salvaçión, el que a de naçer con guisa de tu salvaçión [el Mesías] le hagas nacer con tu salvaçión, haz con nos tus bienes tarde, mañana confiamos en ti, recontaremos tu loor, bendízenos a todos en uno con luz de tu presençia, dístenos ley, vida, merced, piedad, justedad de fuerça, de paz, amén.

6. «'Alenu» (ADC, leg. 316 exp. 4573)

Somos obligados de alabar en todo y por todo, para dar gracias al Señor que crió el comienço, que no nos hizo como los gentiles de la tierra, ni puso nuestra parte como la de ellos, que ellos se 
humillen a vano y vazío, hazen oración a Dios que nos los salva, nosotros nos humillamos ante el rey de los reyes, Señor de los Señores, santo y vendito que es tenido en los çielos y encimientó la tierra, morada y fortaleza, sabrás y pensarás en tu coraçón que Adonay es el Señor en los cielos de arriba y en la tierra de abaxo, que no ay otro sino él. Deshechado son los otros afuera dél así como está escripto en su santificada ley, esperaré en el Señor, demandalle he merced y gracia de legua con ayuntamiento de gentes, hablaré con contar al barón que es la limpieça del coraçón con la fragación de la casa santa. En nuestros días, amén, en nuestras noches, amén, en nuestra vida sea fraguada la ciudad de Sión, sea tu sacrifiçio en Jerusalén, amén, con liçencia de los presentes, plega a ti Señor de engrandecer la ley y de honralla por amor de los atalantes [?] de la tierra ...

\section{7. «Canto grados» (ADC, leg. 316 exp. 4573)}

Canto grados, alçaré al Señor mis ojos, a los montes del Señor vendrá mi ayuda, mi vandeo, mi consejo, mi remedio, Adonay, criador de los çielos y de la tierra, no dará tropieço el Señor en los mis pies, no mires, Señor, mis goardas que son goardas de Ysrael, que el Señor me guardará sobre mi mano derecha el sol del día, no se me fará la luna de la noche, no se me escurezca, guarde el Señor mi vida, mi alma, mi salida, mi venida de peligros y contrarios, amén.

\section{8. «Alaven al Señor» (ADC, leg. 316 exp. 4573)}

Alaven al Señor todos los ángeles, alaven al Señor todos los archángeles, alaven al Señor la nieve y el hielo y el frío y el calor, todas las cosas que os movéis en las aguas, aguas y pescados alavad al Señor por sus marabillas, alavalde por su grandeza viudas y huérfanos, viejos con los mançebos alavad el santo nombre del Señor, cielos que soys sobre los çielos alavad al Señor porque dixo soy otro no, alabalde porque será en el comienço, alavalde porque será en el fin, alavalde los ayres de tormenta, alavalde los ayres de la tierra que viene el plazo en la casa de la orita [?] así como dizen el verso dicípulo de los sabidores, habló Salomón con sabiduría, dize: más vale la buena fama que buen olio, apártate de aqueste mundo con buena nombradía y sepas que la dádiva del buen galardón que dan a los justos es para gloria del otro mundo, y verás 
hijos de tus hijos, y paz sobre Hisrael, paz sea Señor sobre mí y sobre todo mi linage, sed y paz y medicina buena sea para que te sirva y alave. Amén.

9. «Líbrame Señor como libraste a Daniel» (ADC, leg. 316 exp. 4574)

Líbrame Señor como libraste a Daniel del lago [?] de los leones para que yo te sirva, líbrame Señor como libraste a Jonás profeta del vientre de la vallena en las onduras de la mar para que yo te sirva.

\section{APÉNDICE 2}

LISTA DE MIEMBROS DE LA FAMILIA MORA CONDENADOS POR LA INQUISICIÓN

- Juan González: relajado en 1496 (AHN, leg. 154 exp. 365).

- Hernando de Mora: relajado el 25/09/1496 (ADC, leg. 331 exp. 4733).

- Marí López: reconciliada el 2/02/1516 (ADC, leg. 331 exp. 4733).

- Marí López de Mora: suspensa en 1564 (ADC, leg. 232 exp. 2919).

- Lope de Mora: condenado al exilio en 1565 (ADC, leg. 324 exp. 2987).

- Diego de Mora: causa de inhabilitación en 1565, relajado el 16/08/1592 (ADC, leg. 319 exp. 4607).

- Hernando de Mora: condenado el 18/04/1565, relajado el 16/08/1592 (ADC, leg. 320 exp. 4618).

- Juan de Mora: inhabilitado el 5/05/1565, relajado el 18/03/1592 (ADC, leg. 234 exp. 2996).

- Juana de Mora: causa de inhabilitación el 7/05/1565 (ADC, leg. 235 exp. 3010).

- Elvira del Campo: reconciliada en 1569 (AHN, leg. 138 exp. 125).

- Juan de Mora: condenado el 13/07/1573, relajado el 8/07/1598 (ADC, leg. 331 exp. 4733).

- Pedro de Sauca: absuelto en 1588 (ADC, leg. 315 exp. 4560).

- Hernando de Sauca: absuelto en 1588 (ADC, leg. 315 exp. 4560).

- Leonor Ruiz: condenada en 1589 (ADC, leg. 551 exp. 6918).

- Isabel de Mora: reconciliada el 5/07/1589 (ADC, leg. 327 exp. 4689).

- Alonso Martínez de Mora: reconciliado en 1590 (ADC, leg. 329 exp. 4706). 
- Francisco Navarro: reconciliado el 12/08/1590 (ADC, leg. 322 exp. 4639).

- María de Villanueva: reconciliada el 12/08/1590 (ADC, leg. 319 exp. 4606).

- Pedro de Mora: reconciliado el 12/08/1590 (ADC, leg. 712 exp. 786).

- Luisa Mnez de Mora: reconciliada el 12/08/1590 (ADC, leg. 314 exp. 4553).

- Juana de Mora: reconciliada el 12/08/1590 (ADC, leg. 235 exp. 3010).

- Beatriz de Mora: relajada el 12/08/1590 (ADC, leg. 318 exp. 4586).

- Isabel de Mora: reconciliada el 12/08/1590 (ADC, leg. 317 exp. 4585bis).

- Juan de Mora: reconciliado el 12/08/1590 (ADC, leg. 322 exp. 4632).

- María de Mora: reconciliada el 12/08/1590 (ADC, leg. 322 exp. 4631).

- Francisca de Mora: reconciliada el 12/08/1590 (ADC, leg. 314 exp. 4555).

- Julián de Mora: reconciliado el 12/08/1590 (ADC, leg. 318 exp. 4587).

- Juan López de Armenia: reconciliado en 1590-1591 (AHN, leg. 182 exp. 506) (vid. infra 16/08/1592).

- Beatriz Gómez Bedoya: relajada en 1591 (ADC, leg. 330 exp. 4721).

- Juan de Mora: «pedimiento del fiscal contra él» el 5/04/1591 (ADC, leg. 712 exp. 793).

- Francisco de Vega: reconciliado en 1592 (AHN, leg. 187 exp. 841).

- Ana del Campo: reconciliada en 1592 (AHN, leg. 187 exp. 841).

- Inés de Mora: relajada el 3/03/1592 (ADC, leg. 324 exp. 4651).

- Juan López de Armenia: reconciliado el 16/08/1592 (ADC, leg. 283 exp. 3946) (vid. supra 1590-1591).

- Lope de Mora: reconciliado el 16/08/1592 (ADC, leg. 322 exp. 4635).

- Isabel de Mora: reconciliada el 16/08/1592 (ADC, leg. 324 exp. 4647).

- María de Mora: reconciliada el 16/08/1592 (ADC, leg. 313 exp. 4549).

- Catalina de Mora: reconciliada el 16/08/1592 (ADC, leg. 321 exp. 4620bis).

- Antonio de Mora: reconciliado el 16/08/1592 (ADC, leg. 324 exp. 4652). 
- Cristóbal de Mora: reconciliado el 16/08/1592 (ADC, leg. 321 exp. 4621).

- Alvaro de Mora: relajado el 16/08/1592 (ADC, leg. 281 exp. 3907).

- Diego de Mora: relajado el 16/08/1592 (ADC, leg. 246 exp. 3288).

- Francisco de Mora: relajado el 16/08/1592 (ADC, leg. 329 exp. 4703bis).

- Leonor Enríquez: reconciliada el 16/08/1592 (ADC, leg. 327 exp. 4691).

- Ana de Mora: reconciliada el 16/08/1592 (ADC, leg. 320 exp. 4619).

- Rodrigo del Campo: reconciliado el 16/08/1592 (ADC, leg. 321 exp. 4627).

- Inés del Campo: reconciliada el 16/08/1592 (ADC, leg. 320 exp. 4620).

- Catalina Navarro: relajada el 16/08/1592 (ADC, leg. 321 exp. 4626).

- Pedro del Campo: condenado el 10/04/1593 (ADC, leg. 327 exp. 4690).

- Alonso de la Vega: relajado en 1594 (AHN, leg. 187 exp. 841).

- Catalina de Mora: relajada el 13/12/1598 (ADC, leg. 326 exp. 4682).

- Isabel de Villaescusa: relajada el 13/12/1598 (ADC, leg. 330 exp. 4722).

- Francisco de Mora: incompleto (ADC, leg. 315 exp. 4562).

- Catalina de Villanueva: incompleto (ADC, leg. 711 exp. 752).

- Luisa de Mora: incompleto (ADC, leg. 316 exp. 4572).

- Pedro de Mora: incompleto (ADC, leg. 712 exp. 785). 


\section{RESUMEN}

Análisis de una represión inquisitorial llevada a cabo a finales del reinado de Felipe II contra los Mora de Quintanar de la Orden, los cuales formaban una comunidad de judaizantes autóctonos que consiguieron escapar del fenómeno de aculturación general que se produjo entre la mayoría de los conversos castellanos. Tal resistencia, debida en parte a motivos coyunturales externos e internos (tregua inquisitorial entre 1520 y 1580 en la zona meridional del distrito y fuerte solidaridad en el seno del grupo), aporta una nueva prueba de la supervivencia del criptojudaísmo peninsular en plena época de la Contrarreforma.

\section{SUMMARY}

Survey on an inquisitorial repression lead at the end of the reign of Felipe II against the Mora's of Quintanar de la Orden. Those latter constituted an authoctonous community of crypto-Jews who escaped from the general phenomenon of acculturation known by most Castillan conversos. This resistance brings the proof of surviving crypto-judaism at the time of Counter Reformation. 